\title{
Additive Effect of Oral Insulin and an Oral GLP-1 Agonist on Postprandial Glucose Excursions in a Porcine Model
}

\author{
Miriam Kidron*1, Yael Greenberg-Shushlav ${ }^{2}$, Roy Eldor $^{1}$ and Ehud Arbit ${ }^{1}$ \\ ${ }^{* 1}$ Oramed Pharmaceuticals Ltd., Hi-Tech Park, Givat Ram, Jerusalem, Israel \\ ${ }^{2}$ Preclinical Services, Menora St., Kfar Ha'oranim, Israel
}

*Correspondence to: Dr. Miriam Kidron, Oramed Pharmaceuticals Ltd., Hi-Tech Park 2/4 Givat Ram PO Box 39098 Jerusalem, 91390, Phone: +972-2-566-0001, Fax: +972-2-566-0004; Email: miriam@oramed.com

Received: August 08, 2017; Accepted: August 20, 2017; Published: August 25, 2017;

\begin{abstract}
Combination therapy of insulin and a GLP-1 agonist injections is an attractive therapeutic approach in patients with type 2 diabetes mellitus, offering robust glycemic control, a reduced risk of hypoglycemia and weight gain and complementary mechanisms of action. Available combinations of basal insulin preparations and GLP-1 agonists have been shown to be effective and well tolerated in clinical trials. An oral alternative for such combination therapy may improve patient comfort and adherence while potentially offering the added value of liver directed insulin. The aim of this study was to investigate the concomitant pre-prandial delivery of enteric-coated oral insulin (ORMD-0801) and oral exenatide (ORMD-0901) capsules in pigs. The capsules were delivered directly to the duodenum under endoscopic guidance and blood glucose concentrations were monitored over the ensuing three hours. Preprandial delivery of ORMD-0901 or ORMD-0801 fully prevented a post-meal glycemic excursion ( $\mathrm{p}=0.002$ and $\mathrm{p}=0.086 \mathrm{respectively)}$. When given together, a sharp decline $>50 \%$ of mean baseline values in glycemia was observed, suggesting an additive effect. Peak glycemia was 5.2 -fold lower than mean peak values measured in control animals at $\sim 75$ min after feeding $(\mathrm{p}<0.0001)$. We conclude that co-administration of oral insulin and oral exenatide compared with its components was more effective in controlling postprandial glycemia. The robust additive effect suggests a potential for complementary and non-attenuating mechanisms of action of this oral combination.
\end{abstract}

Key words: oral insulin, oral exenatide, ORMD-0801, ORMD-0901, combination therapy, T2DM

\section{Introduction}

Type 2 diabetes is characterized by a relative insulin deficiency in combination with hyperglucagonemia, insulin resistance and often obesity [1-3]. A common therapeutic approach to address these metabolic defects combines basal insulin analogs with glucagon-like peptide-1 (GLP-1), concomitantly providing an insulin replacement with the added and complementary benefit of incretin-mediated increases in post-prandial insulin, inhibition of glucagon secretion and weight loss. [2, 4-6]. Several such combinations are currently in different stages of clinical development, including the combination of insulin degludec and the GLP-1 agonist liraglutide (marketed under the brand name Xultophy), [7-9] and the GLP-1 agonist lixisenatide combined with insulin glargine (LixiLan) [10].

Both GLP-1 analogs and insulin are protein-based drugs, currently marketed as injectable preparations only. An oral preparation, whereby the drug is absorbed through the gastrointestinal tract (GIT) and directly into the porto-hepatic venous system, may be better received by patients and perhaps offer a more physiologic mechanism of action, mimicking the hepatic first-pass effect of endogenously secreted insulin and reducing the relative hyperinsulinemia associated with subcutaneous injections. We have previously reported on a specially designed base formulation of this nature that has been shown to enhance GIT absorption of the active proteins and protect them from hydrolysis in the gut [11]. The basis of the enabling technology lies in protein encapsulation, which protects the proteins during transit through the harsh acidic gastric environment and enables them to reach the small intestines, where the capsule is disintegrated in a $\mathrm{pH}$-dependent manner. The plant-derived protease inhibitors (PIs) incorporated into the formulation, provide for further protection from pancreatic and brush border proteases in the small intestines. The approach mimics that observed in neonates, where PIs are naturally incorporated in the maternal colostrum to facilitate transport of critical macromolecules, such as immunoglobulins, growth factors and antigens across the intestinal epithelial barrier [12]. We present here the results of a pre-clinical factorial study examining the postprandial pharmacodynamic effect in pigs of co-administration of oral human insulin (ORMD-0801) and oral Exenatide, a short-acting GLP-1 agonist (ORMD-0901), as compared to no treatment and the individual agents alone.

\section{Methods and Materials}

This study was approved by the Israeli Council of Animal Experimentation, Ministry of Health. Three fasting female, commercial pigs (Ibelin Farm, Israel; age: 3-4 months-old; weight $25-30 \mathrm{~kg}$ ) were treated in up to eight sessions each, with a minimum two-day washout period between treatments. Animals were housed individually in concrete pens, in a temperature-controlled room $\left(18-24^{\circ} \mathrm{C}\right)$, on a 12:12 light-dark cycle (light hours [07:00 - 19:00]), with olfactory contact between animals. The pigs had free access 
to water by low pressure drinking nipples. Fasting animals were anesthetized with isoflurane ( $2 \mathrm{~L} \mathrm{O}_{2}$ per minute and $5 \%$ isoflurane), intubated and mechanically ventilated. Pigs were positioned on their left side while enteric-coated capsules were administered directly to the duodenum under endoscopic guidance. On test days when both ORMD-0801 and ORMD-0901 were administered, ORMD0901 (150 mg) was delivered first, followed by the ORMD-0801 (8 mg) capsule within 2-10 minutes. The pigs were fed Denkavit powdered milk for pigs (10 g/kg body weight) $30 \mathrm{~min}$ after drug administration and after recovering from anesthesia (10-15 minutes). Blood glucose was monitored via blood samples periodically drawn from a central line catheter over the 240-min post-dosing period. Piglets were intravenously treated with gentamycin $(100 \mathrm{mg} / 10 \mathrm{~kg})$ after every experiment day, to avoid infection. In cases where glucose concentrations dropped below $30 \mathrm{mg} / \mathrm{dL}$, pigs were administered pig chowder and glucose concentrations were monitored for 30 minutes thereafter. Upon completion of the set of experiments, animals were euthanized with intravenously administered pentobarbital $1 \mathrm{ml} / 1.5 \mathrm{~kg}$ body weight.

\section{Results}

When preprandially treated with ORMD-0901 alone or ORMD0801 alone, blood glucose excursions were significantly curbed, as compared to untreated meals (Figure 1). When ORMD-0901 and ORMD-0801 were administered together, a robust drop in blood glucose which was significantly greater than following treatment with each drug alone, was observed (Figure 1; p-value $<0.001$ ). Blood glucose concentrations dropped to hypoglycemic levels ( $20 \mathrm{mg} /$ dL) which were 5.2 -fold lower than mean peak values measured in control meals at $\sim 75$ min after feeding $(\mathrm{p}<0.0001)$ and remained at a low of $>50 \%$ below baseline values until the end of the 180 -minute monitoring session.

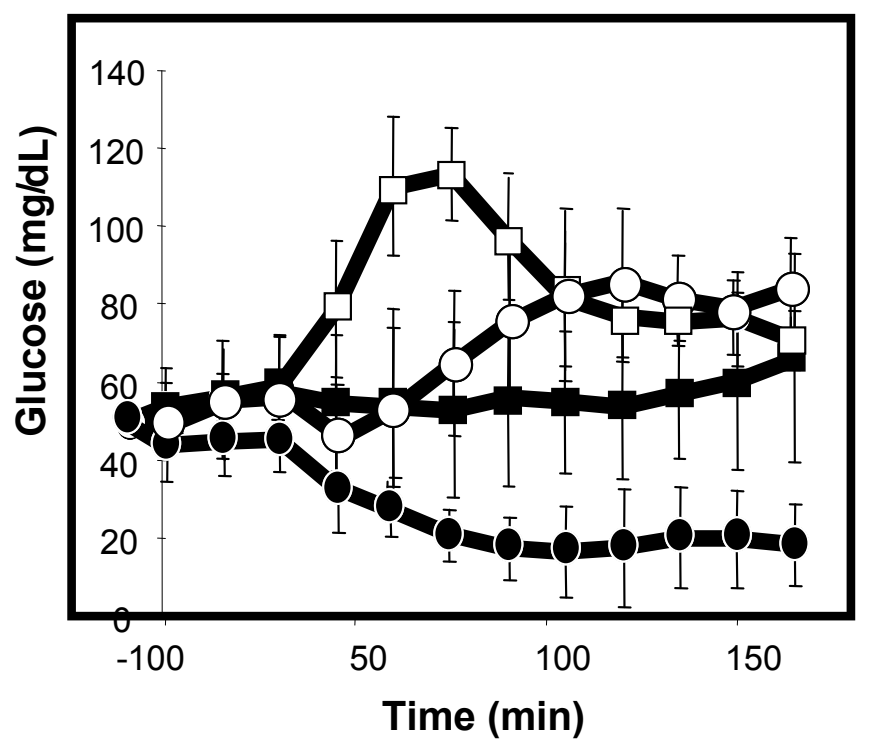

Figure 1. Blood glucose profiles following concomitant delivery of oral exenatide and oral insulin to pigs.
Fasting, commercial pigs were treated with ORMD-0901 (150 mg exenatide; squares), ORMD-0801 (8 mg insulin; triangles) or both ORMD-0901 and ORMD-0801 (circles) capsules, 30 minutes before caloric intake. Blood samples $(1 \mathrm{~mL})$ were periodically drawn throughout the 180-minute observation period to determine glucose concentrations.

\section{Discussion}

This pre-clinical factorial study assessed the feasibility of simultaneous oral delivery of two hormones with complimentary modes of action [13]. Oral co-administration of human insulin and exenatide, provided a robust antihyperglycemic effect, curbing postprandial glucose excursions. The extent of the combined effect suggests an additive effect, resulting in a glycemic drop to a significantly hypoglycemic range. In the proposed combination regimen, insulin deficiency is supplemented by exogenous insulin administration, which is expected to increase glucose utilization and retard hepatic glucose production through direct actions in muscle, adipose tissue and the liver. At the same time, the GLP-1 analog was integrated to stimulate endogenous glucose-responsive insulin secretion, inhibit glucagon secretion and slow gastric emptying [2]. In addition, the GLP-1 component has been reported to induce satiety, lead to decreased food intake and eventually reduce body weight [14]. Moreover, owing to the glucose-dependent insulinotropic effect of GLP-1 and because glucagon-like peptide-1 receptor agonists (GLP-1RAs) preserve or even augment the glucagon response to hypoglycemia $[2,15]$ the GLP-1RA-insulin combination is likely to allow for a reduction in insulin doses.

The importance of the hepatoportal system and liver, as they relate to insulin, is well known, [16] but existence of a hepato-preferential effect of incretin hormones is less clear at this time. As with insulin, there is a hepato-systemic GLP-1 gradient in the portal circulation, with several fold higher GLP-1 concentrations than in the systemic circulation [17]. Accumulating data suggest a role for GLP-1 in the liver and portal system in glucose and fat metabolism, as well as in satiety [18]. Among its known hepatic effects, GLP-1 stimulates glycogen synthesis in isolated rat hepatocytes, [19] and suppresses hepatic glucose production independently of plasma insulin, glucagon and glucose levels [20]. In both animal models [21] and humans [22] treatment with exendin-4 or liraglutide decreased hepatic lipid content and inflammation and decreased hepatic steatosis. While the GLP-1R is expressed on hepatic portal vagal afferents, suggesting indirect mediation of GLP-1 effects by central nervous system (CNS) activity, evidence regarding the presence of GLP-1R on hepatocytes remains conflicting.

Several injectable combinations of long-acting basal insulin and long- or short-acting GLP-1 analogs are in different stages of clinical development. This study is unique in that we show a robust antihyperglycemic effect of the combination of both an oral shortacting insulin and an oral short-acting GLP-1 agonist. The oral absorption of insulin and GLP-1 analog is enabled by Oramed's core technology and formulation. This proprietary technology is comprised of a combination of encapsulation to shield the polypeptide (GLP-1) during transit in the gastrointestinal tract and protease inhibitors 
that reduce its proteolytic degradation. The protease inhibitors are plant derived and comprised of a-chymotrypsin inhibitors. The encapsulation consist of a polymer with $\mathrm{pH}$-dependent solubility that relies on $\mathrm{pH}$ gradients in the intestine for site-specific dissolution [23]. Taken together, the encouraging results presented here, along with the projected long-term clinical benefits of the combined therapy, warrant clinical studies with such short - prandial combinations in patients with diabetes.

The limitations of the study include the absence of a true placebo/ sham endoscopic procedure, the lack of pharmacokinetic (PK) analyses for both exenatide and insulin and the small number of animals examined. Given that the study was a preliminary study, it was deemed acceptable to withhold administration of a placebo before the meal challenge. As for insulin PK, the clear hypoglycemic effect suggests a significant increase in peripheral insulin. Whether this is the result of the administered oral insulin or endogenously secreted insulin in response to the effect of exenatide in the context of a meal and absorbed glucose remains to be determined. Since up to $80 \%$ of secreted insulin is sequestered within the liver upon first-pass metabolism, resulting in minimal doses in the peripheral circulation $[24,25]$ estimation of insulin bioavailability and PK analyses would not have provided useful information, unless there is direct sampling from the portal vein . Furthermore, under physiologic circumstances, endogenous secretion of insulin is a dynamic process, whereby the levels of secreted insulin change from moment to moment depending on ambient glucose levels [26]. As for exenatide PK analyses, non-proprietary analytical methods for the quantitation of exenatide, such as immunoassay (ELISA) and high-performance liquid chromatographic-tandem mass spectrometry (HPLC/MS/MS) method are plagued by low precision, poor repeatability and specificity and also potential interferences by endogenous compounds [27]. Only recently has a commercial and validated enzyme-linked immunosorbent assay kit (Phoenix Pharmaceuticals, Inc., Burlingame, CA, USA) become available for procurement. Nonetheless, the pharmacodynamic observations of the additive effect of the combination treatment compared to no treatment or to treatment with insulin or exenatide alone are compelling and it is unlikely that this significant effect could be attained short of the combined effect of insulin and exenatide.

\section{Authorship}

MK: Conception and design of study, drafting and revising manuscript

YGS: Acquisition of data, analysis and interpretation

RE: Conception and design of study, drafting and revising manuscript

EA: Conception and design of study, drafting and revising manuscript

\section{Acknowledgements}

The authors would like to acknowledge and thank Yehudit Posen, $\mathrm{Ph} . \mathrm{D}$ for her invaluable assistance in preparing this manuscript.

\section{Abbreviations}

CNS: central nervous system

ELISA: enzyme-linked immunoabsorbent assay
GIT: gastrointestinal tract

GLP-1: glucagon-like peptide-1

GLP-1RA: glucagon-like peptide-1 receptor agonist

HPLC: high performance liquid chromatography

MS: mass spectrometry; PI: protease inhibitor

PK: pharmacokinetics

\section{Competing Interests}

MK is the CTO and hold shares at Oramed Pharmaceuticals.

YGS, RE and EA are consultants at Oramed.

\section{References}

1. Inzucchi S, Bergenstal R, Buse JB, Diamant M, et al. (2012) Management of hyperglycaemia in type 2 diabetes: a patient-centered approach. Position statement of the American Diabetes Association (ADA) and the European Association for the Study of Diabetes (EASD). Diabetologia.

2. Holst JJ, Vilsbøll T (2013) Combining GLP-1 receptor agonists with insulin: therapeutic rationales and clinical findings. Diabetes, Obesity and Metabolism.

3. Ahrén B (2013) Incretin dysfunction in type 2 diabetes: clinical impact and future perspectives. Diabetes \& Metabolism.

4. Balena R, Hensley I, Miller S, Barnett A (2013) Combination therapy with GLP-1 receptor agonists and basal insulin: a systematic review of the literature. Diabetes, Obesity and Metabolism.

5. Eng C, Kramer CK, Zinman B, Retnakaran R (2014) Glucagon-like peptide-1 receptor agonist and basal insulin combination treatment for the management of type 2 diabetes: a systematic review and meta-analysis. Lancet.

6. Young LA, Buse JB (2014) GLP-1 receptor agonists and basal insulin in type 2 diabetes. Lancet 384: 2180-2181. [crossref]

7. Gough SC, Bode B, Woo V, Rodbard HW, et al. (2014) Efficacy and safety of a fixed-ratio combination of insulin degludec and liraglutide (IDegLira) compared with its components given alone: results of a phase 3, open-label, randomised, 26-week, treat-to-target trial in insulin-naive patients with type 2 diabetes. Lancet Diabetes Endocrinol.

8. Buse JB, Vilsbøll T, Thurman J, Blevins TC, Langbakke IH, et al. (2014) Contribution of liraglutide in the fixed-ratio combination of insulin degludec and liraglutide (IDegLira). Diabetes Care 37: 2926-2933. [crossref]

9. Gough SC, Bode BW, Woo VC, Rodbard HW, Linjawi S, et al. (2015) One-year efficacy and safety of a fixed combination of insulin degludec and liraglutide in patients with type 2 diabetes: results of a 26 -week extension to a 26-week main trial. Diabetes Obes Metab 17: 965-973. [crossref]

10. Riddle MC, Aronson R, Home P, Marre M, et al. (2013) Adding once-daily lixisenatide for type 2 diabetes inadequately controlled by established basal insulin a 24-week, randomized, placebo-controlled comparison (GetGoal-L). Diabetes Care.

11. Kidron M, Bar-On H, Berry EM, Ziv E (1982) The absorption of insulin from various regions of the rat intestine. Life Sci 31: 2837-2841. [crossref]

12. Drozdowski LA, Clandinin T, Thomson A (2010) Ontogeny, growth and development of the small intestine: Understanding pediatric gastroenterology. World J Gastroenterol 16:787-99.

13. Ahrén B (2014) Insulin plus incretin: A glucose-lowering strategy for type 2-diabetes. World J Diabetes 5: 40-51. [crossref]

14. Steinert RE, Beglinger C, Langhans W (2016) Intestinal GLP-1 and satiation: from man to rodents and back. Int J Obes (Lond) 40: 198-205. [crossref]

15. Farngren J, Persson M, Schweizer A, Foley J, et al. (2014) Glucagon dynamics during hypoglycaemia and food-re-challenge following treatment with vildagliptin in insulin-treated patients with type 2 diabetes. Diabetes Obes Metab.

16. DeFronzo RA, Ferrannini E (1987) Regulation of hepatic glucose metabolism in humans. Diabetes Metab Rev 3: 415-459. [crossref]

17. Holst JJ (2007) The physiology of glucagon-like peptide 1. Physiol Rev 87: 14091439. [crossref]

18. Sandoval DA, D'Alessio DA1 (2015) Physiology of proglucagon peptides: role of glucagon and GLP-1 in health and disease. Physiol Rev 95: 513-548. [crossref]

19. Valverde I, Morales M, Clemente F, López-Delgado MI, Delgado E, et al. (1994) Glucagon-like peptide 1: a potent glycogenic hormone. FEBS Lett 349: 313-316. [crossref]

20. Seghieri M, Rebelos E, Gastaldelli A, Astiarraga BD, Casolaro A, et al. (2013) Direct effect of GLP-1 infusion on endogenous glucose production in humans. Diabetologia 56: 156-161. [crossref] 
21. Ding X, Saxena NK, Lin S, Gupta NA, Anania FA (2006) Exendin-4, a glucagonlike protein-1 (GLP-1) receptor agonist, reverses hepatic steatosis in ob/ob mice. Hepatology 43: 173-181. [crossref]

22. Eguchi Y, Kitajima Y, Hyogo H, Takahashi H, et al. (2015) Pilot study of liraglutide effects in non-alcoholic steatohepatitis and non-alcoholic fatty liver disease with glucose intolerance in Japanese patients (LEAN-J). Hepatol Res.

23. Karsdal MA, Riis BJ, Mehta N, Stern W, Arbit E, et al. (2015) Lessons learned from the clinical development of oral peptides. Br J Clin Pharmacol 79: 720-732. [crossref]

24. Eaton RP, Allen RC, Schade DS (1983) Hepatic removal of insulin in normal man: dose response to endogenous insulin secretion. J Clin Endocrinol Metab 56: 1294 1300. [crossref]
25. Meier JJ, Holst JJ, Schmidt WE, Nauck MA (2007) Reduction of hepatic insulin clearance after oral glucose ingestion is not mediated by glucagon-like peptide 1 or gastric inhibitory polypeptide in humans. Am J Physiol Endocrinol Metab 293:E849-E856.

26. Bergman R (2000) Non-esterified fatty acids and the liver: why is insulin secreted into the portal vein? Diabetologia 43:946-952.

27. Zhang J-F, Sha C-J, Sun Y, Gai Y-Y, et al. (2013) Ultra-high-performance liquid chromatography for the determination of exenatide in monkey plasma by tandem quadrupole mass spectrometry. J Pharm Analysis.

\section{Citation:}

Miriam Kidron, Yael Greenberg-Shushlav, Roy Eldor and Ehud Arbit (2017) Additive Effect of Oral Insulin and an Oral GLP-1 Agonist on Postprandial Glucose Excursions in a Porcine Model. Endocrinol Diabetes Metab J Volume 1(3): 1-4 